\title{
The Research-Practice Gap in Management Field: A Relational Approach Based on the Quintuple Helix Model
}

\author{
Jesús de Frutos-Belizón ${ }^{1}$, Fernando Martín-Alcázar ${ }^{1}$ \& Gonzalo Sánchez-Gardey $^{1}$ \\ ${ }^{1}$ University of Cádiz, Spain \\ Correspondence: Jesús de Frutos-Belizón, University of Cádiz, Spain. Email: jesus.defrutos@uca.es
}

Received: October 14, 2018

Accepted: November 6, 2018

Online Published: November 14, 2018

doi:10.5430/ijba.v9n6p52

URL: https://doi.org/10.5430/ijba.v9n6p52

\begin{abstract}
The academic literature in the field of Management is often criticized because of its little relevance to the professional community. The literature maintains that a considerable gap has been created between research and practice in this discipline, suggesting the need to develop more literature that can unite both communities. A sizeable body of literature has been developed with the objective of analysing and proposing different remedies and solutions to this important problem. In this work, we offer a vision of the current state of literature in this topic and the different currents that have focused on proposing solutions to this problem. Thus, we guide the readers towards understanding the existing gaps and how each approach aims to fill them by your study. Moreover, drawing on them, we propose the theoretical perspective of the Quintuple Helix as a relevant perspective to describe the relationships between professionals and academics, and how the disconnections between them can be managed. Therefore, this work contributes to the existing literature with the proposal of the Quintuple Helix model as a framework to establish a communicative structure and stronger links between both communities.
\end{abstract}

Keywords: research-practice divide, rigour-relevance gap, quintuple helix

JEL Classification: M0, M10

\section{Introduction}

A sizeable body of literature has been developed to provide evidence of the existing separation between scholars and professionals in management field. This so-called research-practice gap is explained in that (1) the academic community focuses research on topics that are not relevant to the professional community, (2) the scientific findings are not generated in a way that is easily applicable, or (3) they are simply not "translated" and accessible to professionals (Kelemen \& Bansal, 2002; Bansal et al., 2012; Bartunek \& Rynes, 2014; Bullinger, Kieser \& Schiller-Merkens, 2015). Academics do not frame research questions that are of professional interest, or that contain important practical implications. Instead, they focus on answering research questions raised from the academic literature itself. Similarly, professionals do not strive to put into practice the findings obtained by the academic community to solve their problems in organizations (Gill, 2018).

This topic is one of the biggest problems facing the management discipline, generating a lot of work and debates in the literature that have tried to explain and provide solutions to try to close the gap between both communities (Cohen, 2007; Bartunek \& Rynes, 2014; Bullinger et al., 2015; Kieser et al., 2015; Gill, 2018). In fact, the most relevant journals in this field of knowledge have dedicated special issues on this issue. For example, Academy of Management Journal (2001), British Journal of Management (2001), Human Resources Management (2004), Journal of Management Studies (2009), Organization Studies (2010), Academy of Management Perspectives (2012) and the Journal of Business Economics (2014).

In the same way, different solutions have been proposed in order to try to bring positions between both communities and close the problematic gap. For example, specific journals that call themselves "bridges" between both communities, try to translate the scientific findings for a professional audience (Human Resource Management, Academy of Management Perspectives or Academy of Management Discoveries). Attempts have also been made to bring the academic literature closer to the professional community through publication in more accessible media such as books and monographs. Examples are the Locke's (2009) Handbook of Principles of Organizational Behavior and Armstrong's (2006) Handbook of Human Resource Management Practice. Even specific associations 
have been created that act as intermediaries between professionals and academics (Bansal et al., 2012). These associations organize spaces, carry out activities or provide tools for the interaction of professionals and academics. An example is the Leading Edge Consortium, the Labour and Employment Relations Association (LERA) or the Network for Business Sustainability (NBS).

Despite all these proposals, and after developing an important body of literature with the aim of closing this gap, this discussion continues today to be a matter of importance in the discipline of management (Banks et al., 2016; Gill, 2018).

In this paper, we contribute to the literature initially by offering a current perspective of the problem that arises. Later, considering the inputs of the different perspectives reviewed, we propose a model based on the Quintuple Helix, to discuss how the academic and practitioner disciplines can be connected. Finally, the article concludes with some recommendations that could help develop this approach and close the gap

\section{The Research-Practice Gap in Management Discipline}

There is a certain consensus in the literature that the origin of the gap can be placed in the establishment of management as a scientific discipline. In the middle of the last century, two reports published by two important foundations in the United States criticized the lack of scientific content in the main business schools (Gordon \& Howell, 1959, Pierson, 1959). These reports placed greater emphasis on scientific rigor and questioned the scientific foundations of management education. In response, there is an important "scientification" in the discipline, adopting the positivist model of the natural sciences and developing a more rigorous research. However, paradoxically, this scientific rigor to the detriment of relevance to users and professionals is considered the origin of the problem. Scientific research in the discipline of management was losing interest for professionals while gaining greater rigor. This disconnection has been growing and is still present today (Kelemen \& Bansal, 2002; Gulati, 2007; Daft \& Lewin, 2008; Bansal et al., 2012).

Despite its well-known origin, some papers argue that, in addition, today academics are more motivated to produce knowledge than to translate it and disseminate it in an accessible way to the professional community (Van de Ven \& Johnson, 2006; Khurana, 2007). Other works also argue that the gap is truly insurmountable due to the different languages or the different epistemological approaches that each community represents (Kelemen \& Bansal, 2002; Kieser \& Leiner, 2009; 2012). In line with these arguments, Shapiro et al. (2007) identified two different moments that are considered the source of the problem. On the one hand, the transfer of scientific results to practitioners can get "lost in translation". This is related to the problems that occur in the transfer of scientific knowledge, and finds explanation in which academic journals seem to be written by researchers. On the other hand, academic research may also be "lost before translation". The scientific literature is not easily translatable for practice because its arguments are based on a completely different logic. In addition, the issues addressed by the academic literature do not represent the real problems that professionals have.

A relevant body of literature that studies the problem of the gap advocates "rigorous" academic research as opposed to the need for relevance on the part of the professional community (Van de Ven \& Johnson, 2006; Bartunek \& Rynes, 2014). There seems to be a consensus that rigor in academic research represents the accuracy and conciseness in the research tasks, and that therefore, refers to principles such as validity or methodological soundness (Flickinger et al, 2014). Those works that satisfy these principles are considered with greater legitimacy and higher scientific quality within the institutional reference frame (Flickinger et al, 2014). Conversely, we understand that academic research is relevant if it influences management practices and thereby affects organizational performance (Nicolai \& Seidl, 2010).

Some scholars strongly suggest that scientific rigor and practical relevance can hardly be mutually considered (Daft \& Lewin, 2008; Kieser \& Leiner, 2009). Generally, the demands that suggest bringing the academic literature closer to the professional world involve diverse and difficult competences that are not typically possessed by academics. Moreover, paradoxically, the combination of skills necessary in the development of relevant knowledge is considerably different from those necessary in the development of scientifically rigorous research (Tucker \& Lowe, 2014). Daft and Lewis (2008) argued that academic literature should have the main mission of publishing diverse innovative ideas for academics, without taking into account the practical importance for the professional community. Some academics consider that excessive emphasis on practical relevance interferes with the production of independent, high-quality and rigorous knowledge (Daft \& Lewis, 2008; Kieser \& Leiner, 2009). Greater rigor is related to scientific validity and accuracy. In this sense, an article is assessed in consideration if it demonstrates a methodological validity and meets the requirements proposed by the reviewers. Because of this, reviewers normally insist on corrections about methodological and theoretical issues, and are comparatively less concerned about the 
discussion of the study's professional implications. Those works that show a greater rigor lend more trustworthiness to their results, and are considered as more acceptable and legitimate (Flickinger et al., 2014). As a consequence, "management science is in danger of losing its legitimacy because it lacked distance to practice" (Kieser \& Leiner, 2009:528). Opposing considerations can be found in other streams of the literature. We find other studies where different authors have argued that rigor and relevance do not have to be considered as two opposite principles in management research (Gulati, 2007; Flickinger et al., 2014). In fact, some streams in the literature, such as evidence-based management, that supports its foundations in the assumption that the research in management field must be rigorous and at the same time show practical relevance (Rosseau, 2006).

In order to offer a vision of the different approaches that have proposed different solutions to this problem, we review the literature and classify the works developed into three fundamental currents. Moreover, we also guide the readers towards understanding the existing gaps and how each approach aims to fill them by your study. First, there is a set of works that are grouped around the ideas of Mode 2 (Gibbons et al., 1994). These works suggest that in order to solve the gap, it is necessary that academics and professionals work collaboratively together in the development of research. From this perspective, professionals and academics, from local knowledge and scientific knowledge, can develop relevant and rigorous quality research at the same time (e.g. Van de Ven \& Johnson, 2006, Shani \& Coghlan, 2014). Examples of these streams are action research (Eden \& Huxham, 1996), collaborative research (Amabile et al, 2001, Van de Ven \& Johnson, 2006) and design sciences (Van Aken, 2005; Hodgkinson \& Starkey, 2011; Shani \& Coghlan, 2014).

In contrast to this first approach we identify in the literature another group of studies that oppose these ideas. This stream of work, led by the studies of Kieser \& Leiner $(2009,2012)$, suggests that professionals and academics are positioned in separate, closed and self-referential systems (Seidl, 2005). These works understand that professionals do not possess the knowledge and scientific competences required to collaborate in research. Based on systems theory, they argue that both communities cannot cross the boundaries established between systems, and that therefore, rigorous and quality collaborative research cannot be generated (Daft \& Lewis, 2008; Kieser \& Leiner, 2009; 2012; Bartunek, 2011).

We find a third stream of work that can be placed in the middle of the two approaches we have discussed. This approach understands that it is necessary to maintain a certain distance between both communities, but to intensify relationships at key moments of the research (Bansal et al., 2012; Bartunek \& Rynes, 2014). In this way, the identity and methods of each community are maintained. Within this approach we find is what Kieser et al. (2015) denominates the popularization view. These works focus the cause of the problem on a deficit structure that ensures the transfer, communication and relations between professionals and academics (Kelemen \& Bansal, 2002; Cohen, 2007; Rynes et al., 2007; Bansal et al., 2012; Kieser et al., 2015). Another group of works, named by Kieser et al. (2015) as the institutional view (Bennis \& O'Toole, 2005; Buckley et al., 1998) suggests that the gap arises from the disconnections between the academic literature and the academic training received by professionals in scientific institutions and business schools. According to these works, the formative content of the business schools is too obsolete and is far from the updated content of the academic literature. Therefore, they propose as a solution to more closely align management education with the content of academic literature, exchanges between business schools and professionals or internships of teachers in organizations (Buckley et al., 1998, Bennis \& O'Toole, 2005). Another group of works that we can include within this current is the evidence-based management (Kieser et al., 2015, Rousseau et al., 2008). This perspective suggests that to get the research to the professionals it is necessary to synthesize the scientific knowledge based on the foundations based on the best evidence obtained in organizational practices (Rousseau et al., 2008).

In some way, all the streams in the literature reflect a common advocacy for intensifying the relations between the communities, but considering the academia and the management profession as two separate worlds, with different values and objectives. Thus, considering the inputs of the different perspectives reviewed, we propose a model based on the Quintuple Helix, to discuss how the academic and practitioner disciplines can be connected.

\section{Bridging the Valley Between Management Research and Practice: A Proposed Model Based on the Quintuple Helix}

As it has been explained before, different authors, drawing on the Systems Theory, maintained that the professional-academic gap cannot be closed because the systems of science and practice in our field respond to completely different logics. Yet from the opposite perspective, other currents have defended collaborative research based on Mode 2 generation of knowledge. We believe that the theoretical approach of the Quintuple Helix offers an ideal framework within which to resolve academic-professional differences. As illustrated in Figure 2, the Quintuple 
Helix depicts knowledge generation in society arising from collective links and knowledge transfer between the following five subsystems or helices: (1) the science system, (2) the economic system, (3) the natural environment, (4) civil society, and (5) the political system (Carayannis \& Campbell, 2010).

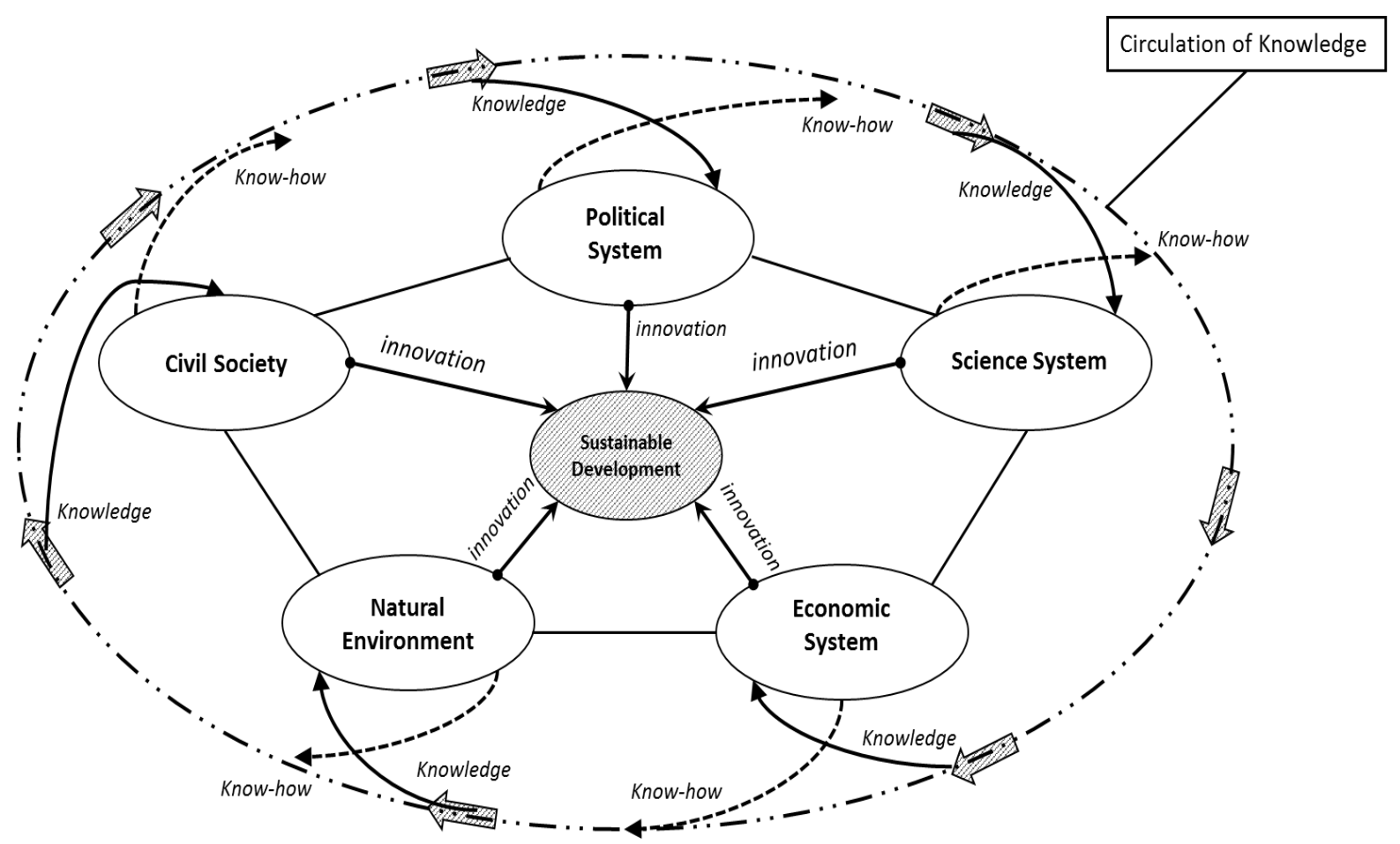

Figure 1. The quintuple helix model

Source: Carayannis and Campbell $(2010 ; 2012)$

In the Quintuple Helix model, knowledge is considered as the elemental force and driver of progress. The Quintuple Helix model takes the sum of social interactions and academic exchanges in a state to provide a visualization of a co-operative system of knowledge, know-how and innovation for sustainable development (Carayannis \& Campbell, 2010:62). This model suggests that innovation should be considered an evolutionary and interactive process that requires intense communication and collaboration between societal actors such as universities, governments and companies. As we have seen previously, relational approaches emphasized the promotion of relationships between professionals and academics, and both should play independent roles. In the Quintuple Helix model, each of the five subsystems makes a certain contribution to the generation, transmission and utilization of knowledge in society (Carayannis \& Campbell, 2010; Carayannis et al., 2012). According to the model, the science system is defined in relation to academia, universities or scientific institutions. These institutions are responsible for originating scientific and technological knowledge, and ultimately for forming the human capital that makes up society (Carayannis et al., 2012). The second subsystem, the economic system, is composed by the industry, organizations and banks. This system assumes functions related to the innovation and application of knowledge, which are concretized in the creation of wealth and value in society, concentrating the economic capital of the state (Carayannis et al., 2012). The third helix of the model corresponds to government. The political system deploys an appropriate regulatory framework to promote growth environments and regulate the political constraints in which knowledge generation and the exploitation cycle unfold (Carayannis et al., 2012). The fourth helix refers to civil society, where the knowledge and innovations generated are intended to achieve a welfare state. Carayannis and Campbell extend the foundations of Quadruple Helix by adding a fifth corresponding helix to the natural environment to the model. The Quintuple Helix takes a socio-ecological perspective of the natural environments of society, considering a new subsystem that takes into account the natural environment as a fundamental and equivalent component of the generation of knowledge and innovation (Carayannis \& Campbell, 2012). Under the ideas represented by the model of the Quintuple helix, the natural environments that contextualize society and the economy must also be considered as engines of innovation and the generation of knowledge (Carayannis and Campbell, 2010). The Quintuple Helix 
thus, proposes an adequate basis for theory and practice to understand the relationships between knowledge and innovation, and ecologically sustainable development. This is a differentiating element of this approach.

On the other hand, both the Quintuple Helix model and its predecessor models (the Triple Helix and Quadruple Helix) include intermediate organizations between the various subsystems that make up society (Liljemark, 2004; Delman $\&$ Madsen, 2007). These organizations collaborate as enablers and facilitators of innovation and expand its impact; they are valued to be important actors in innovation systems. They are in the border zones of the pillars of the helices, linking the organizations in each helix. These organizations are related to the Networks for Business Sustainability, to which were previously described by Bansal et al. (2012).

As seen in Figure 2, the Quintuple Helix model proposes the generation of relevant knowledge for problem-solving and sustainable development, and indicates how socioecological transition can go hand in hand with knowledge production and innovation (Carayannis \& Campbell, 2012). Knowledge in a Quintuple Helix model is the central element, the main driver of progress and innovation. The resource of "knowledge" circulating between social subsystems constitutes the innovations that occur in society and in the economy. This transfer for each of the subsystems that make up the model involves qualities of an input and output of subsystems for the knowledge generated (Carayannis \& Campbell, 2012). As Carayannis \& Campbell (2006:4) argued, "knowledge serves as an input or resource for advanced societies and economies, which increasingly depend on knowledge. On the other hand, knowledge production (knowledge creation) also generates knowledge as an output, which then is being fed back (recycled) as a knowledge input". Because this circulation constantly stimulates the generation of new knowledge, all the subsystems influence one another; for example, in the academic world, when formulating research questions and generating knowledge are influenced by the needs of professionals in the economic subsystem. This may occur through intermediary organizations (Bansal et al., 2012), joint interpretative forums or professional-academic conferences. Similarly, the academic world can better transmit knowledge to the professional world by improving the translation of its generated knowledge, through better presentation of implications for practice in articles (Bartunek \& Rynes, 2010), by publishing in practitioner as well as academic language (Kieser \& Leiner, 2012) or by publishing in more journals for professionals. For their part, researchers generating knowledge also relate to government systems when they receive or justify funding for research. Likewise, the research generated must comply with the regulations imposed by the political system. In the same way, the academic world will oversee the formation of the human capital that makes up civil society, which, in turn, will communicate its needs to stimulate research to examine specific topics. Finally, the science system should consider the natural environment in which its knowledge is contextualized, to achieve ecologically sustainable development.

From our point of view, the Quintuple Helix model can guide the integrating and sustainable development of the academic literature in response to professional needs. For example, the management of the motivation of workers or the management of labour conciliation. Both subsystems, academic and professional, could be approached with the collaboration of intermediate organizations in forums or collaborative environments. The literature developed should be framed within the labour regulations imposed by the political subsystem. In turn, the political subsystem must obtain information from the economic and civil subsystem to develop financing programs that encourage the academic community to investigate relevant topics. Finally, this research should be contextualized in the application environment, represented by the natural subsystem.

\section{Discussion and Conclusion}

The organization of existing literature around their theoretical foundations facilitates the discussion and proposal of different actions oriented to bridge this gap. Following our review of the literature, the model proposed in this paper support a relational approach to bridge the academic-practitioner gap. We argue that management academic-practitioner gap could be, in some ways, highly productive by creating a kind of tension that drives relevant knowledge. These arguments highlight the need to manage the disconnections between the communities of practice and research in management field (Bansal et al., 2012; Bartunek \& Rynes, 2014; Kieser \& Leiner, 2012). However, to carry out this relational approach through the different stages of the knowledge generation process, it is necessary to propose different recommendations and promote different changes that make possible the connections between both communities.

Based on these considerations, we believe that it is possible to suggest solutions from two viewpoints. On the one hand, we should be more effective in tailoring our research to the needs of professionals; on the other hand, we should also improve the visibility of scientific skills and increase the value of using these skills for organizational performance. 
For example, we need to establish meetings or forums to reach a joint interpretation of the real needs of professionals, in which the implementation of the knowledge generated by the academics could also be discussed. Having highlighted the role that limitations of communication have as one of the causes of the gap between academics and professionals (Kelemen \& Bansal, 2002; Bansal et al., 2012; Bartunek \& Rynes, 2014; Bullinger et al., 2015), we believe it necessary to pursue this matter further. Sometimes, these forums have been defined in the academic literature as meetings where individuals can promote their views on a particular situation as well as collectively exchange and re-examine those aspects, ultimately changing and improving their perspectives (Mohrman et al., 2008). In line with this, Cohen (2007) suggested the need to build discussion forums where both communities reach agreement on research questions. These confrontations could contribute to both sides of the gap to better understand and deepen the interests of the other community, enabling closer cooperation. Moreover, as we have indicated previously, in the era of communications and based on the assumption that a poor transfer infrastructure is one of the causes that generate the gap, web-enabled communication tools could help to alleviate these limitations in a real way. For example, virtual forums or symposia are ideal scenarios for both communities to learn about the most relevant problems. Similarly, academics could reach out practitioners to explore respective possibilities to carry out relevant research. In this way, academics and practitioners from different locations and organizations would have the possibility to participate in this type of events.

Other alternatives, such as the translation of research in books aimed at professionals, could also help bridge the gap between the two communities. The academic literature that can be disseminated through divulgative books may have greater recognition for the professional community than the publications in scientific journals. The books that have as main audience the professionals must show the scientific evidence obtained but written for a more general audience. They should include information relevant to professionals, in addition to scholarly information. However, to establish fluent and efficient communication in both forums and publications, academics should develop bilingual and 'bi-competent' skills so that they are able to flexibly apply scientific knowledge to provide professional solutions and contribute to theory production. Therefore, it is not enough for the academic community to transfer their findings through a language for practice and academia, but it is also necessary to use schemes between both sides of the gap (Kieser \& Leiner, 2009; 2012).

Similarly, it would be especially enriching to deepen the role of Management education today. Rynes et al. (2007) suggested that managers should be exposed to formal training to get further competences to understand and translate to practice scientific theories. In many cases, this contents are not covered because most textbooks do not discuss research findings, and business schools' managers have recently put a stronger emphasis on hiring faculties with professional experience, rather than a scholar training (Cohen, 2007). Academics must structure, formulate and disseminate a common body of relevant and applied scientific knowledge to be transmitted to professionals (Langbert, 2005). As Cohen (2007:1014) argued, "if textbooks are written by academicians, why wouldn't they include research findings translated for practical application?". Textbooks should articulate a knowledge that is closer to scientific evidence, although written for an average student. In addition, they must be formulated on relevant knowledge for the professional community, and in turn, scientific rigor (Cohen, 2007). Management is a fragmented field of knowledge, distributed across different academic units, so it would be advisable to develop a unified strategy, with solid -although multidisciplinary- theoretical underpinnings. With this approach, it would be easier for Management academics to demonstrate the potential contribution of Management theory as a major strategic component for organizations, not only through their research findings, but also through the knowledge transmitted to their graduates and their performance within organizations.

On the other hand, focusing on the second view of our considerations, we believe that it is necessary that the academics of our field convince to the professionals of the profits that the academic abilities have for an organization. The tasks that the manager performs within the modern organizations have experienced great changes in recent years, and it continues evolving nowadays (Hiltrop, Despres \& Sparrow, 1995). Organizations must constantly explore innovative sources of competitive advantage and many of these sources rely on a more effective management of people-related issues. Today's organizational management is facing problems related to a continuously growing population, whose average age is significantly increasing in nearly all advanced economies. Other challenges to face are the incessant and irreversible deterioration of the environment, the greater inequalities of classes or the growing poverty (DeNisi et al., 2014). Managers should provide valuable inputs to manage these conditions, articulating policies related to labour ethics, corporate social responsibility or the management of increasingly diverse workplaces. All these new managerial elements will have greater importance in the near future for moderns' organization, which cannot respond to them applying the same strategies and traditional theoretical approaches. This is why academics can contribute with our scientific skills to improve organizational performance and effective 
problem solving. Academic community have the task of increasing the valuation and visibility of the scientific abilities that we possess, since from a professional perspective there is no knowledge of the benefit of these qualities. Academics can bring a different vision, based on scientific and academic rationality, contributing to offer alternatives to organizational problems. The contribution of academic skills could be very useful to organizations because they would have the opportunity to consider their problems from two interconnected realities: academic and professional.

Finally, it is important to note that with this work we contribute to the existing literature with the proposal of a novel perspective that can serve as a framework to establish a communicative structure and stronger links. We offer a base on which to deepen the development of sustainable links, under the foundations of the Quintuple helix. In addition, this approach could also guide the development of future empirical work on this topic. Conversely, we also want to point out that the present work does not try to offer any specific solution or explicit evidence of how to bring both communities closer together. We understand that it is too ambitious an objective that demands more studies that deepen in this matter. However, we want to be measured by pointing out that our work, rather, opens a way to develop more literature on a relational perspective that is framed in the foundations of the Quintuple helix model.

\section{Acknowledgement}

Authors are ordered alphabetically. This study has benefited from financing from the Research Project ECO2014-56580-R of the Spanish Ministry of Economy and Competitively, and the Research Projects P12-SEJ-1810 and P12-SEJ-1618 from the Andalusia Government (Spain) and PR2016-018 (Research Projects University of Cadiz).

\section{References}

Armstrong, M. (2006). A handbook of human resource management practice. Kogan Page Publishers.

Banks, G., Pollack, J., Bochantin, J., Kirkman, B., Whelpley, C., \& O’Boyle, E. (2016). Management's sciencepractice gap: A grand challenge for all stakeholders. Academy of Management Journal, 59(6), 2205-2231. https://doi.org/10.5465/amj.2015.0728

Bansal, P., Bertels, S., Ewart, T., MacConnachie, P., \& O’Brien, J. (2012). Bridging the research-practice gap. Academy of Management Perspectives, 26(1), 73-92. https://doi.org/10.5465/amp.2011.0140

Bartunek, J.M. (2011). What has happened to Mode 2?. British Journal of Management, 22(3), 555-558. https://doi.org/10.1111/j.1467-8551.2011.00773.x

Bartunek, J.M., \& Rynes, S.L. (2010). The construction and contributions of "implications for practice": What's in them and what might they offer? Academy of Management Learning and Education, 9(1), 100-117.

Bartunek, J.M., \& Rynes, S.L. (2014). Academics and practitioners are alike and unlike: The paradoxes of academic-practitioner relationships. Journal of Management, 40(5), 1181-1201. https://doi.org/10.1177/0149206314529160

Bennis, W.G., \& O’Toole, J. (2005). How business schools lost their way. Harvard Business Review, 83(5), 96-104.

Buckley, M.R., Ferris, G.R., Bernardin, H.J., \& Harvey, M.G. (1998). The disconnect between the science and practice of management. Business Horizons, 41(2), 31-38. https://doi.org/10.1016/S0007-6813(98)90032-5

Bullinger, B., Kieser, A., \& Schiller-Merkens, S. (2015). Coping with institutional complexity: Responses of management scholars to competing logics in the field of management studies. Scandinavian Journal of Management, 31, 437-450. https://doi.org/10.1016/j.scaman.2015.02.001

Carayannis, E.G., \& Campbell, D.F.J. (2010). Triple Helix, Quadruple Helix and Quintuple Helix and how do knowledge, innovation and the environment relate to each other? A proposed framework for a trans-disciplinary analysis of sustainable development and social ecology. International Journal of Social Ecology and Sustainable Development, 1(1), 41-69. https://doi.org/10.4018/jsesd.2010010105

Carayannis, E.G., Barth, T.D., \& Campbell, D.F.J. (2012). The Quintuple Helix innovation model: Global warming as a challenge and driver for innovation. Journal of Innovation and Entrepreneurship, 1(2), 1-12. https://doi.org/10.1186/2192-5372-1-1

Cohen, D.J. (2007). The very separate worlds of academic and practitioner publications in human resource management: Reasons for the divide and concrete solutions for bridging the gap. Academy of Management Journal, 50(5), 1013-1019. https://doi.org/10.5465/amj.2007.27151946 
Daft, R.L., \& Lewin, A.Y. (2008). Rigor and relevance in organization studies: Idea migration and academic journal evolution. Organization Science, 19, 177-183. https://doi.org/10.1287/orsc.1070.0346

Delman, J., \& Madsen, S.T. (2007). Nordic triple helix collaboration in knowledge, innovation, and business in China and India: A preliminary study. NIAS-Nordic Institute of Asian Studies, Copenhagen.

DeNisi, A.S., Wilson, M.S., \& Biteman, J. (2014). Research and practice in HRM: A historical perspective. Human Resource Management Review, 24(3), 219-231. https://doi.org/10.1016/j.hrmr.2014.03.004

Flickinger, M., Tuschke, A., Gruber-Muecke, T., \& Fiedler, M. (2014). In search of rigor, relevance and legitimacy: What drives the impact of publications?. Journal of Business Economics, 84, 99-128. https://doi.org/10.1007/s11573-013-0692-2

Gibbons, M., Limoges, C., Nowotny, H., Schwartzman, S., Scott, P., \& Trow, M. (1994). The new production of knowledge. The Dynamics of Science and Research in Contemporary Societies. London: Sage.

Gill, C. (2018). Don't know, don't care: An exploration of evidence based knowledge and practice in human resource management. Human Resource Management Review, 28(2), 103-115. https://doi.org/10.1016/j.hrmr.2017.06.001

Gordon, R.A., \& Howell, J.E. (1959). Higher education for business. The Journal of Business Education, 35(3), 115-117. https://doi.org/10.1080/08832323.1959.10116245

Gulati, R. (2007). Tent poles, tribalism, and boundary spanning: The rigor-relevance debate in management research. Academy of Management Journal, 50(4), 775-782. https://doi.org/10.5465/amj.2007.26279170

Hiltrop, J. M., Despres, C., \& Sparrow, P. (1995). The changing role of HR managers in Europe. European Management Journal, 13(1), 91-98. https://doi.org/10.1016/0263-2373(94)00061-B

Hodgkinson, G. P., \& Starkey, K. (2011). Not simply returning to the same answer over and over again: Reframing relevance. British Journal of Management, 22(3), 355-369. https://doi.org/10.1111/j.1467-8551.2011.00757.x

Kelemen, M., \& Bansal, P. (2002). The conventions of management research and their relevance to management practice. British Journal of Management, 13(2), 97-108. https://doi.org/10.1111/1467-8551.00225

Khurana, R. (2007). From Higher Aims to Hired Hands: The Social Transformation of American Business Schools and the Unfulfilled Promise of Management as a Profession. Princeton and Oxford: Princeton University Press.

Kieser, A., \& Leiner, L. (2009). Why the rigour-relevance gap in management research is unbridgeable. Journal of Management Studies, 46(3), 516-533. https://doi.org/10.1111/j.1467-6486.2009.00831.x

Kieser, A., \& Leiner, L. (2012). Collaborate with practitioners: But beware of collaborative research. Journal of Management Inquiry, 21, 14-28. https://doi.org/10.1177/1056492611411923

Kieser, A., Nicolai, A., \& Seidl, D. (2015). The practical relevance of management research: Turning the debate on relevance into a rigorous scientific research program. The Academy of Management Annals, 9(1), 143-233. https://doi.org/10.5465/19416520.2015.1011853

Langbert, M. (2005). The master's degree in HRM: midwife to a new profession?. Academy of Management Learning \& Education, 4(4), 434-450. https://doi.org/10.5465/amle.2005.19086785

Liljemark, T. (2004). Innovation Policy in Canada. Strategy and Realities. Swedish Institute for Growth Policy Studies: Stockholm.

Locke, E. (2011). Handbook of principles of organizational behavior: Indispensable knowledge for evidence-based management. John Wiley \& Sons.

Mohrman, S., Pasmore, W., Shani, A.B., Stymne, B., \& Adler, N. (Eds.). (2008). Toward Building a Collaborative Research Community. Los Angeles, CA: Sage. https://doi.org/10.4135/9781412976671.n30

Nicolai, A., \& Seidl, D. (2010). That's relevant! Different forms of practical relevance in management science. Organization Studies, 31(9-10), 1257-1285. https://doi.org/10.1177/0170840610374401

Pierson, F.C. (1959). The Education of American Businessmen: A Study of University College Programs in Business Administration. New York, NY: McGraw-Hill.

Rousseau, D.M. (2006). Is there such a thing as "evidence-based management"? Academy of Management Review, 31(2), 256-269. https://doi.org/10.5465/amr.2006.20208679 
Rousseau, D.M., Manning, J., \& Denyer, D. (2008). Evidence in management and organizational science: Assembling the field's full weight of scientific knowledge through syntheses. Academy of Management Annals, 2(1), 475-515. https://doi.org/10.5465/19416520802211651

Rynes, S.L., Giluk, T.L., \& Brown, K.G. (2007). The very separate worlds of academic and practitioner periodicals in human resource management: Implications for evidence-based management. Academy of Management Journal, 50(5), 987-1008. https://doi.org/10.5465/amj.2007.27151939

Seidl, D. (2005). Organisational Identity and Self-Transformation: An Autopoietic Perspective. Aldershot, UK: Ashgate.

Shapiro, D.L., Kirkman, B.L., \& Courtney, H.G. (2007). Perceived causes and solutions of the translation problem in management research. Academy of Management Journal, 50(2), 249-266. https://doi.org/10.5465/amj.2007.24634433

Tucker, B.P., \& Lowe, A.D. (2014). Practitioners are from Mars; academics are from Venus? An empirical investigation of the research-practice gap in management accounting. Accounting, Auditing \& Accountability Journal, 27(3), 394-425. https://doi.org/10.1108/AAAJ-01-2012-00932

Van Aken, J.E. (2005). Management research as a design science: Articulating the research products of Mode 2 knowledge production in management. British Journal of Management, 16(1), 19-36. https://doi.org/10.1111/j.1467-8551.2005.00437.x

Van de Ven, A.H., \& Johnson, P.E. (2006). Knowledge for theory and practice. Academy of Management Review, 31(4), 802-821. https://doi.org/10.5465/amr.2006.22527385 